Journal of Mathematics and Statistics 6 (3): 342-346, 2010

ISSN 1549-3644

(C) 2010 Science Publications

\title{
A Random Walk Model for Stock Market Prices
}

\author{
${ }^{1}$ S.O.N. Agwuegbo, ${ }^{2}$ A.P. Adewole and ${ }^{3}$ A.N. Maduegbuna \\ ${ }^{1}$ Department of Statistics, University of Agriculture, Abeokuta, Nigeria \\ ${ }^{2}$ Department of Computer Science, University of Agriculture, Abeokuta \\ ${ }^{3}$ Department of Banking and Finance, Paul University, Awka
}

\begin{abstract}
Problem statement: The stock exchange market has been one of the most popular investments in the recent past due to its high returns. The market has become an integral part of the global economy to the extent that any fluctuation in this market influences personal and corporate financial lives and the economic health of a country. The daily behavior of the market prices revealed that the future stock prices cannot be predicted based on past movements. Approach: In this study, we analyzed the behavior of daily return of Nigerian stock market prices. The sample included daily market prices of all securities listed in the Nigeria Stock Exchange (NSE). Results: The result from the study provided evidence that the Nigerian stock exchange is not efficient even in weak form and that NSE follow the random walk model. The idealized stock price in the Nigerian stock exchange is a martingale. Conclusion: Martingale defines the fairness or unfairness of the investment and no investor can alter the stock price as defined by expectation.
\end{abstract}

Key words: Econometric techniques, forecasting, Markov chain, martingale, random walk, stock market

\section{INTRODUCTION}

The stock market forecasting is marked more by its failure than by its successes since stock prices reflect the judgments and expectations of investors, based on the information available. If things look good, the price moves upward so quickly that recipient of cheerful information has little or no time to act upon it. Remarkably, efforts have been made to apply econometric techniques of model building in the prediction of stock prices in an effort to demonstrate that the market fluctuations are essentially unpredictable (Bernstein and Bostain, 1974; Black, 1971; Brealey and Myers, 1996; Buhlmann, 2005).

Fama and French (1988) have argued that there are long term pattern in stock prices with several years of upswing followed by more sluggish periods. According to Fama (1965; 1995), a stock market where successive, price changes in individual securities are independent is, by their definition a random walk market. According to Kendal (1953), stock prices following a random walk implies that the price changes are as independent of one another as the gains and losses. The independence assumption of the random walk model is valid as long as knowledge of the past behavior of the series of price changes cannot be used to increase expected gains.

More specifically, if successive price changes for a given security are independent, there is no problem in timing purchases and sales of that security. A simple policy of buying and holding the security will be as good as any more complicated mechanical procedure for timing purchases and sales (Fama, 1965,1995).

In this study, the random walk approach is presented with the specific aim of giving a definite description of the Nigerian stock market prices. In a world without interest rates, idealized stock prices should be martingales. This is one way of formulating the so called efficient market hypothesis (Buhlmann, 2005; Fama, 1965; 1995).

The random walk model: Let $\mathrm{X}_{\mathrm{t}}$ be the price of stock on any particular day t. At each subsequent time unit, $\mathrm{X}_{\mathrm{t}}$ varies in an unpredictable fashion such that during each time unit the stock price moves its location either one unit left ward, or one unit right ward or it remains the same.

We suppose that the system can either remain in $i$, or move to state $\mathrm{i}-1$ or to state $\mathrm{i}+1$ and the random direction of each jump is independent of all earlier jumps.

More specifically, if $\mathrm{S}_{\mathrm{n}}$ denotes the location of the stock prices at time $\mathrm{n}$ the overall behavior of the sequence $\left(S_{n}\right)$ is of the form:

$$
\mathrm{S}_{\mathrm{n}}=\mathrm{X}_{0}+\mathrm{X}_{1}+\mathrm{X}_{2}+\ldots \ldots \ldots \ldots \ldots \ldots+\mathrm{X}_{\mathrm{n}}
$$


where the $X_{n}$ are independent random variables.

Therefore:

$$
\mathrm{S}_{\mathrm{n}}=\mathrm{S}_{0}+\sum_{\mathrm{j}=1}^{\mathrm{n}} \mathrm{x}_{\mathrm{j}}
$$

Where:

$\mathrm{S}_{0}=$ The starting position

$\mathrm{x}_{\mathrm{j}}=$ Independent and identically distributed random variables each taking either the value -1 with probability $\mathrm{q}$, or the value +1 with probability $\mathrm{p}$, or remain the same at value 0 with probability $r$

Generating function: The main interest is to determine the distribution of $S_{n}$ for finite $n$ given assumptions about the distribution of the $\mathrm{x}_{\mathrm{j}}$. Intuitively, given:

$$
\mathrm{S}_{\mathrm{n}}=\sum_{\mathrm{j}=1}^{\mathrm{n}} \mathrm{x}_{\mathrm{j}}
$$

We suppose that the system can be in one of the enumerable sequence of states denoted by $S_{1}, S_{2}, \ldots \ldots, S_{n}$. If $S_{n}$ takes different values for different states, then the conditional distribution of $S_{n+1}$ given $\mathrm{S}_{\mathrm{n}}, \mathrm{S}_{\mathrm{n}-1}, \ldots \ldots \ldots, \mathrm{S}_{0}$ can be written as:

$$
P\left\{S_{n+1}=i_{n+1} / S_{n}=i_{n}, S_{n-1}=i_{n-1}, \ldots \ldots \ldots . . . . S_{0}=i_{0}\right\}
$$

and if the Markovian property is satisfied, this is always equal to:

$\mathrm{P}\left\{\mathrm{S}_{\mathrm{n}+1}=\mathrm{i}_{\mathrm{n}+1} \backslash \mathrm{S}_{\mathrm{n}}=\mathrm{i}_{\mathrm{n}}\right\}$

Equation 5 is also known as the nearest neighbor property. Since the idea of a nearest neighbor system does not involve any preferred direction of time, we then consider only what happens when a Markov chain is observed as $\mathrm{n}$ decreases in value instead of increasing. These provide a complete description of a Markov process.

Martingale technique: It is clear that the investors in stocks may make certain choices at each investment on how to invest, of which the choice may depend on the past history of the stock prices.

The expected fortune of the investors after trial $n+1$ is:

$E\left\{S_{n+1}=i_{n+1} \backslash S_{n}=i_{n}, S_{n-1}=i_{n-1},--S_{i}=i_{1}, S_{0}=i_{0}\right\}$

If (6) is equal $S_{n}$, the investment is fair.

The investment by the investors is fair for all $n$ when:
$\mathrm{E}\left\{\mathrm{S}_{\mathrm{n}+1}=\mathrm{i}_{\mathrm{n}+1} \backslash \mathrm{S}_{\mathrm{n}}=\mathrm{i}_{\mathrm{n}}\right\}=\mathrm{S}_{\mathrm{n}}$

We suppose that the expectation in (7) is calculated not only conditionally on the value of $S_{n}$ but also on the whole previous history of the sequence. Such a system is said to be a martingale (Karr, 1993; Williams, 1991; Gerber, 1994).

Martingale (Ito, 1986; Rolski et al., 1999) represents a fair game and sums of independent random variables. Naturally, the investor's unfair investment is said to be a super martingale and the theory of such a system is due to Doob (1953).

We then define an unfair investment by the inequality:

$E\left\{S_{n+1}=i_{n+1} \backslash S_{n}=i_{n}\right\} \leq S_{n}$ for all $n$

No investor can alter the fairness or unfairness of a stock price as defined by expectation. All that can be done is to transform the sequence so that the probability of fairness is increased or decreased while at the same time dividend is increased or decreased.

The defining conditions for a martingale can be given in terms of the difference equation:

$\mathrm{Z}_{\mathrm{n}}=\mathrm{S}_{\mathrm{n}}-\mathrm{S}_{\mathrm{n}-1}$

Where:

$\mathrm{Z}_{\mathrm{n}}=$ Identically distributed

$\mathrm{S}_{\mathrm{o}}=0$ with probability one

Equation 9 has a Markov property and can be seen as a solution to a recursive stochastic equation:

$\mathrm{S}_{\mathrm{n}}=\mathrm{S}_{\mathrm{n}-1}+\mathrm{Z}_{\mathrm{n}}$

Chain dependent model: Let $\left\{S_{n}\right\}$ be a martingale with increment as defined in (10).

Then:

$S_{n}=Z_{1}+Z_{2}+\cdots+Z_{n}$

and are still martingale.

We can think of $Z_{k+1}$ as a score associated with the kth transition.

Let:

$$
\mathrm{S}_{\mathrm{n}}=\sum_{\mathrm{k}=1}^{\mathrm{n}} \mathrm{Z}_{\mathrm{k}}
$$

$\mathrm{S}_{\mathrm{n}}$ is called an additive functional of the Markov chain. The strength of dependence in the Markov chain can be computed from the transition matrix. 
By using Chapman-Kolmogorov equation, we specify the n-step transition probabilities of lower order by an argument that:

$$
\begin{aligned}
& P_{i j}^{(n)}=P\left\{S_{n}=j \backslash S_{o}=i\right\} \\
& \quad=\sum_{k} P\left\{S_{n}=j / S_{n-1}=k, \ldots \ldots . ., S_{o}=i\right\} \\
& =\sum_{k} P\left\{S_{n}=j \backslash S_{n-1}=k,\right\} P\left\{S_{n-1}=k / S_{o}=i\right\} \\
& \quad=\sum_{k} P_{k j} P_{i k}^{(n-1)}
\end{aligned}
$$

Then:

$\mathrm{P}_{\mathrm{ij}}^{(\mathrm{n})}=\sum \mathrm{P}_{\mathrm{ik}}^{(\mathrm{n}-1)} \mathrm{P}_{\mathrm{kj}}$

The state probabilities for time $\mathrm{n}$ are defined as:

$\mathrm{P}_{\mathrm{j}}^{(\mathrm{n})}=\mathrm{P}\left\{\mathrm{S}_{\mathrm{n}}=\mathrm{j}\right\}$

Equation 13 is given by the vector of initial probabilities:

$\mathrm{P}_{\mathrm{i}}^{(\mathrm{o})}=\mathrm{P}\left\{\mathrm{S}_{\mathrm{o}}=\mathrm{i}\right\}$

and the n-step transition matrix such that:

$$
\begin{aligned}
& P_{j}^{(n)}=P\left\{S_{n}=j\right\} \\
& \quad=\sum_{k} P\left\{S_{n}=j \backslash S_{o}=i\right\} P\left\{S_{o}=i\right\} \\
& =\sum P_{i j}^{(n)} P_{i}^{(o)}
\end{aligned}
$$

Therefore:

$\mathrm{P}_{\mathrm{j}}^{(\mathrm{n})}=\sum \mathrm{P}_{\mathrm{i}}^{(\mathrm{o})} \mathrm{P}_{\mathrm{ij}}^{(\mathrm{n})}$

This is completely specified when its transition matrix $\mathrm{P}$ and the initial conditions $\mathrm{P}^{(\mathrm{o})}$ are known. Equation 15 is an ideal procedure in studying the behavior of the system when it is at equilibrium. It shows that we can study the behavior of the system over a short period of time by repeated application of $\mathrm{P}$ to any initial distribution vector. After a sufficient long period of time the system settles down to a condition of statistical equilibrium in which the state occupation probabilities are independent of the initial conditions.

We limit our study to the case where the chain is in a stationary state so that the initial state $\mathrm{P}_{\mathrm{i}}^{(\mathrm{o})}$ will become less relevant to the n-step transition probability as $n$ increases.

The limiting value is defined as: $\lim P\left[S_{n}=j / S_{o}=i\right]=P\left[S_{n}=j\right]=\pi j$

The limiting value is stationery or time invariant. This invariance property of $\pi_{\mathrm{j}}$ is connected with the notion of ergodicity of Markov chain. The ergodicity of the Markov chain then implies that $\pi_{\mathrm{j}}$ is the unique probalistic solution to the system of linear equations. It turns out that:

$\pi_{\mathrm{j}}=\lim \mathrm{P}_{\mathrm{ij}}^{(\mathrm{n})}$

The $\pi_{\mathrm{ij}}$ are strictly positive and independent of i and is a probability function since:

$\sum_{\mathrm{j}=1}^{\mathrm{n}} \pi_{\mathrm{ij}}=1$

The limiting distribution in (17) satisfies the balance equation:

$\pi_{\mathrm{ij}}=\pi_{\mathrm{i}} \mathrm{P}_{\mathrm{ij}}$

Because of the invariance property, each probability solution $\pi_{\mathrm{ij}}$ in (19) is called a stationary initial distribution of $\left\{S_{n}\right\}$. In matrix notation, (19) can be written as:

$\pi=\pi \mathrm{P}$

or equivalently:

$\pi(1-\mathrm{P})=0$

Thus $\pi$ is a left Eigen vector of $\mathrm{P}$ corresponding to the Eigen value 1.

\section{MATERIALS AND METHODS}

Application: The daily stock returns of 60 quoted companies in the Nigeria stock market is used in this study. The chain took into account the behavior of the market for two successive days, for a period of 5 weeks or 20 days, each classified as increase or decrease or remain the same.

The state distribution at the initial state is given by:

$$
\mathrm{P}^{(0)}=[0.417,0.200,0.383]
$$

and the transition matrix $\mathrm{P}$ as:

$$
P=\left[\begin{array}{ccc}
0.4 & 0.2 & 0.4 \\
0.38 & 0.24 & 0.38 \\
0.46 & 0.18 & 0.36
\end{array}\right]
$$


Table 1: State distribution

\begin{tabular}{llll}
\hline Number & $\mathrm{P}_{\mathrm{o}}{ }^{(\mathrm{n})}$ & $\mathrm{P}_{1}^{(\mathrm{n})}$ & $\mathrm{P}_{2}^{(\mathrm{n})}$ \\
\hline 1 & 0.417 & 0.202 & 0.381 \\
2 & 0.420 & 0.200 & 0.380 \\
3 & 0.420 & 0.200 & 0.380 \\
4 & 0.420 & 0.200 & 0.380 \\
5 & 0.420 & 0.200 & 0.380 \\
6 & 0.420 & 0.200 & 0.380 \\
7 & 0.420 & 0.200 & 0.380 \\
8 & 0.420 & 0.200 & 0.380 \\
9 & 0.420 & 0.200 & 0.380 \\
10 & 0.420 & 0.200 & 0.380 \\
\hline
\end{tabular}

Each row of this matrix $\mathrm{P}$ is a probability vector and is a precise statement of Probability for change in the behavior of the stock prices for two successive days.

The state distribution $\mathrm{P}^{(\mathrm{n})}$ have the same limiting vector $\pi_{\mathrm{i}}$ no matter what the initial state distribution $\mathrm{P}^{(\mathrm{o})}$ may be.

The state distribution at one is given by:

$$
\mathrm{P}^{(1)}=[0.417,0.202,0.381]
$$

The state distribution is given in Table 1.

In fact, from time 2-10, the table gives the same vector, implying that $\mathrm{n}$ does not have to be very large before the state distributions in our study become equal to the fixed vector, so at $n=2$ the chain is in a stationary state. The Table 1 reveals that at first difference the distribution is stationary indicating that a random walk model is appropriate to define the stock price movement.

\section{RESULTS}

The result from this study provided evidence to show that individual stocks generally satisfy the random walk hypothesis by using historical stock price data. The study also demonstrated that the Nigerian Stock Exchange (NSE) is not efficient even in the weak form and investment strategies based on past information of the NSE will not necessarily yield higher returns since the price formation is assumed to be a stochastic process.

\section{DISCUSSION}

The increasing prominence of the stock market in Nigeria is one of the most striking features of financial development over the last decade. The Nigerian Stock Exchange (NSE) plays an essential role in raising capital funds and also as a link between firms and the investing public. Empirical studies of the NSE revealed that results can only be derived when the dynamics of the stock prices are known.
The stock price in NSE is a martingale process since only one statement about the conditional expectation is made. If the market is fair, the price fluctuation can be defined based on the sequence of past price changes.

\section{CONCLUSION}

This study describes the theory of random walks and some of the important issues it raises concerning the stock market. A market where there are successive price changes in individual securities is simply a random walk market. The study shows that the stock price changes have no memory of the past history and that no investor can alter the fairness or unfairness of a stock price as defined by expectation.

We can formalize fairness or unfairness in terms of a random walk $\left\{S_{n}, n E I N\right\}$.

The study shows that stock prices is but a martingale and all that investors can do is to narrow discrepancies between fairness and unfairness in a way that high probabilities of small gains may be exchanged for low probabilities of large gains.

The investor is not allowed at any time to invest in the market in a way which might involve his losing more than his investment. There expected fortune after trial $n+1$ is the same as their present fortune as long as the particular investment remains fair or unfair.

\section{REFERENCES}

Bernstein, P.L. and D. Bostian, 1974. How to Forecast the Stock Market. 1st Edn., Prentice-Hall, Inc., Englewood Clift, New Jersey, pp: 450.

Black, F., 1971. Implications of the random walk hypothesis for portfolio management. Finance. Anal. $\quad$ J., $\quad 27$ : $16-22$. http://www.jstor.org/pss/4470785

Brealey, R.A. and S.C. Myers, 1996. Principles of Corporate Finance. 5th Edn., McGraw-Hill Companies, New York, ISBN: 10: 0070074178, pp: 998.

Buhlmann, H., 2005. Mathematical Methods in Risk Theory. 1st Edn., Springer, Oxford, ISBN: 10: 3540051171, pp: 210.

Doob, J.L., 1953. Stochastic Processes. 1st Edn., Wiley, New York, ISBN: 0471218138, pp: 654.

Fama, E.F. and K.R. French, 1988. Permanent and temporary components of stock prices. J. Politic. Econ., $\quad$ 96: 246-273. http://ideas.repec.org/a/ucp/jpolec/v96y1988i2p246 $-73 . h t m l$ 
Fama, E.F., 1965. The behavior of stock-market prices. J. Bus., 38: 34-105. http://www.jstor.org/stable/2350752

Fama, E.F., 1995. Random walks in stock market prices. Finance. Anal. J., 21: 55-59. http://www.jstor.org/stable/4469865

Gerber, H.U., 1994. Martingales and tail probabilities. Astin Bull., 24: 145-146.

Ito, K., 1986. An Introduction to Probability Theory. 1st Edn., Clarendon Press, Oxford, ISBN: 10: 0521269601, pp: 213.

Karr, A.F., 1993. Probability. 1st Edn., Springer, New York, ISBN: 10: 0387940715, pp: 312.
Kendal, M.G., 1953. The analysis of economic timeseries. J. R. Stat. Soc., 96: 11-25.

Rolski, T., S. H. Schmidli, V. Schmidt and J. Teugels, 1999. Stochastic Process for Insurance and Finance. 1st Edn., Wiley, New York, ISBN: 10: 0471959251, pp: 680.

Williams, D., 1991. Probability with Martingales. 1st Edn., Cambridge University Press, Cambridge, ISBN: 10: 0521406056, pp: 272. 